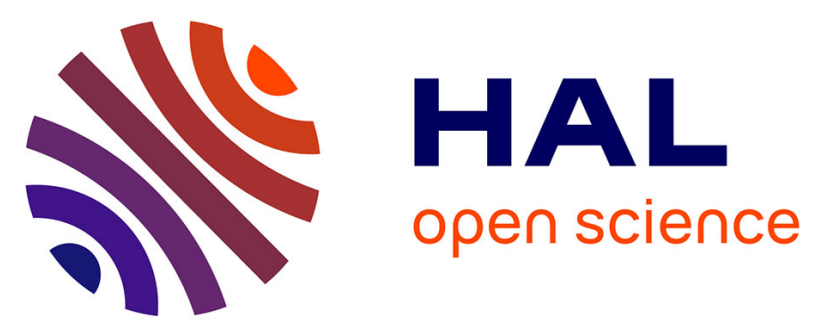

\title{
Novel Non-toxic and Non-hazardous Solvent Systems for the Chemistry of Indoles: Use of a Sulfone-containing Brønsted Acid Ionic Liquid Catalyst in Butyl Acetate
} Ahmed El-harairy, Y. Qi, Meie Yue, Weigang Fan, Florence Popowycz, Yves Queneau, Minghao Li, Yanlong Gu

\section{To cite this version:}

Ahmed El-harairy, Y. Qi, Meie Yue, Weigang Fan, Florence Popowycz, et al.. Novel Non-toxic and Non-hazardous Solvent Systems for the Chemistry of Indoles: Use of a Sulfone-containing Brønsted Acid Ionic Liquid Catalyst in Butyl Acetate. ChemCatChem, 2019, 11 (17), pp.4403-4410. 10.1002/cctc.201900784 . hal-02193181

\section{HAL Id: hal-02193181 \\ https: / hal-udl.archives-ouvertes.fr/hal-02193181}

Submitted on 8 Jul 2020

HAL is a multi-disciplinary open access archive for the deposit and dissemination of scientific research documents, whether they are published or not. The documents may come from teaching and research institutions in France or abroad, or from public or private research centers.
L'archive ouverte pluridisciplinaire HAL, est destinée au dépôt et à la diffusion de documents scientifiques de niveau recherche, publiés ou non, émanant des établissements d'enseignement et de recherche français ou étrangers, des laboratoires publics ou privés. 
Novel non-toxic and non-hazardous solvent systems for the chemistry of indoles: use of a sulfonecontaining Brønsted acid ionic liquid catalyst in butyl acetate

Ahmed El-Harairy, ${ }^{[\mathrm{a}]}$ Yiliqi, ${ }^{[\mathrm{a}]}$ Meie Yue ${ }^{[\mathrm{b}]}$ Weigang Fan, ${ }^{[\mathrm{d}]}$ Florence Popowycz, ${ }^{[\mathrm{d}]}$ Yves Queneau, ${ }^{*[\mathrm{~d}]}$ Minghao Li, ${ }^{[\mathrm{a}]}$ and Yanlong $\mathrm{Gu}^{*}[\mathrm{a}, \mathrm{c}]$

[a] Key Laboratory of Material Chemistry for Energy Conversion and Storage, Ministry of Education. Hubei Key Laboratory of Material Chemistry and Service Failure. School of Chemistry and Chemical Engineering, Huazhong University of Science and Technology, 430074, Wuhan, China.

[b] College of Chemistry and Molecular Engineering, Qingdao University of Science and Technology, 266042, Qingdao, China.

[c] State Key Laboratory for Oxo Synthesis and Selective Oxidation, Lanzhou Institute of Chemical Physics, Lanzhou, 730000, China.

[d] Institut de Chimie et Biochimie Moléculaires et Supramoléculaires, Univ Lyon, CNRS, Université Lyon 1, INSA Lyon, CPE Lyon, ICBMS, UMR 5246 ; Université Claude Bernard, Bâtiment Lederer, 1 Rue Victor Grignard, 69622 Villeurbanne Cedex, France

\begin{abstract}
Dipolar and aprotic solvents are often required in acid-catalyzed reactions, however many of them are listed in solvent selection guides as not-recommended due to their toxicity or explosivity. A catalytic ionic liquid, namely a sulfone-containing imidazolium-based Brønsted acid ionic liquid, which alleviates the detrimental effect of classical dipolar aprotic solvents, was synthesized. This ionic liquid integrates the function of a dipolar aprotic solvent able to stabilize carbocation intermediates and the activating effect of a strong Brønsted acid on electrophiles. The use of this tailor-made ionic liquid was exemplified in some transformation reactions of indoles, which proceeded with high yield and selectivity using a green and an industrially acceptable solvent, butyl acetate. The recyclability of the ionic liquid catalyst was also demonstrated.
\end{abstract}




\section{Introduction}

The indole ring system, one of the most ubiquitous heterocycles in nature, has become an important building block for designing biologically active molecules and pharmaceutical agents benefiting from a great structural diversity. ${ }^{[1]}$ Therefore, the chemistry of indoles, covering synthesis and downstream transformations of indoles, is an important field in organic chemistry. ${ }^{[2]}$ Indole can be considered as a $\pi$ excessive heterocycle having a characteristic enamine embedded in its framework, making its $\mathrm{C} 3$ position strongly nucleophilic. This enables indoles to readily participate in some Friedel-Crafts type electrophilic substitutions, such as halogenations, Mannich and Michael reactions. ${ }^{[3]}$ Many variations of these reactions, including multicomponent and domino reactions, have also been developed. ${ }^{[4]}$ Most of the Friedel-Crafts type reactions of indoles involve the generation of carbocation intermediates. To facilitate the progress of such reactions, acid catalysts are often used in conjunction with dipolar aprotic solvents which stabilize the carbocation intermediate. ${ }^{[5]}$ However, acid-compatible solvents, such as dichloromethane, nitromethane, and 1,4-dioxane, are generally not recommended in all the solvent selection guides due to their toxicity and hazardous property. ${ }^{[6]}$ Therefore, increasing the greenness of the indole-transformation methods in the future will include efforts for finding safer solvent systems. ${ }^{[7]}$

In fact, several safer alternatives to classic dipolar aprotic solvents have been reported recently. We proposed the use of a $\mathrm{NO}_{2}$-functionalized imidazolium-based ionic liquid as a solvent (or a solvent system component) to replace nitromethane, which is an explosive dipolar and aprotic solvent. ${ }^{[8]}$ Some interesting options have also been found in the field of bio-based chemicals, such as cyrene ((-)dihydrolevoglucosenone), ${ }^{[9]} \mathrm{N}$-butylpyrrolidinone, ${ }^{[10]} \gamma$-valerolactone ${ }^{[11]}$ or 2-methyltetrahydrofuran (2MeTHF). ${ }^{[12]}$ Another alternative is the use of solvent-pair mixtures composed of hydrogen bond donor/acceptor (HBD-HBA) couples. ${ }^{[13]}$ Recently, Lipshutz proposed the use of water as a solvent in combination with TPGS-750-M, a bio-based nonionic surfactant, ${ }^{[14]}$ leading to a micellar medium in which organic reactions proceed like in dipolar aprotic media. However, most of the reported alternative solvent are not compatible with acidic conditions. For example, cyrene, an endocyclic acetal, tends to form a complex mixture of products under acidic conditions. ${ }^{[9-\mathrm{g}]}$ Hydrolysis of 2-MeTHF may also occur in the presence of acid, ${ }^{[15]}$ hampering its use in acid-catalyzed reaction.

An alternative strategy has been developed based on the rational design of a tailor-made catalyst which integrates not only the function of dipolar aprotic solvent to stabilize reaction intermediates, but also the activating effect of the acid toward the substrate. In 2014, we reported a sulfone-containing Brønsted acid ionic liquid which is able to act as a unique solvent-conserving catalyst, allowing acid-catalyzed reactions to proceed under solvent-free conditions (Table 1, 1d). ${ }^{[16]}$ The ionic liquid was insoluble in the organic phase, while the high density of polar functional groups created a unique dipolar aprotic microenvironment, allowing the reaction to proceed smoothly and efficiently. Quite recently, Xiao and 
Sun have used a mesoporous material with a high density of polar moieties as a support to anchor sulfonic acid. ${ }^{[17]}$ The solvation environment in the inside pores of this material may be similar to that of DMSO to some extent, enabling the synthesis of 5-hydroxyfurfural from glucose, which is a typical solventdependent reaction, to be performed in tetrahydrofuran. These studies demonstrated explicitly that, by means of wise catalyst design, it is possible to avoid the use of toxic solvents including polar aprotic ones. However, designing generally efficient media to replace dipolar aprotic solvents remains very challenging.

In this work, looking for a more general system able to promote common acid-catalyzed reactions without the need of using dipolar aprotic solvents, we developed a new sulfone-containing imidazoliumbased Brønsted acid ionic liquid. Intriguingly, this ionic liquid is insoluble in weakly polar solvents, allowing us to use butyl acetate, a largely available and industrially acceptable organic solvent, as the reaction medium. The established catalytic system was proved to be very effective for some acidcatalyzed transformations of indoles which normally require the use of toxic and hazardous dipolar aprotic solvents.

\section{Results and Discussion}

The ionic liquid 1c was synthesized using a three-step procedure as shown in Scheme 1, involving (i) heating equimolar amounts of 1-(3-aminopropanyl)imidazole and divinylsulfone in methanol at $60{ }^{\circ} \mathrm{C}$ for $24 \mathrm{~h}$ leading, after removal of the volatile solvent, to the cyclic tertiary amine 1a in nearly quantitative yield; (ii) double quaternization of 1a with 1,3-propanesulfonate giving the imidazolium $\mathbf{1 b}$ as a white solid after filtration and washing with acetone; and (iii) acidification of $\mathbf{1 b}$ with triflic acid to provide targeted compound 1c as a pale-yellow viscous liquid, in $88 \%$ yield over the full three-step synthetic sequence.

It is important to note that ionic liquid 1c is immiscible with organic solvents such as butyl acetate, 1,2dichloroethane, and toluene, and that, very importantly, these solvents were not able to extract triflic acid (TfOH) from 1c (Figure 1, picture b). This behavior is different from that of the ionic liquid 1d previously reported by us, which misses the imidazolium moiety compared to 1c. The triflic acid component in 1d did leach out when an organic solvent able to dissolve $\mathrm{TfOH}$ was added. This was visibly evidenced by the fact that the precursor of $\mathbf{1 d}$, a solid zwitterion salt, was generated and precipitated out, lying in the vial bottom (Figure 1, picture a). Apparently, the core imidazolium-based Brønsted acid ionic liquid structure of 1c, similar to that of Forbes's ionic liquid 1e played a key role in keeping the TfOH component in the ionic phase. ${ }^{[18]}$

The catalytic activity of $\mathbf{1 e}$ was examined in the three-component reaction of 2-methylindole (4a), sesamol (5a), and phenylglyoxal monohydrate (6a), which provides a C3 (indol-3-yl)-substituted benzofuran derivative 7a. Such an assembly of a glyoxal hydrate with an activated phenol and carbon- or 
nitrogen-based nucleophile is a typical acid-catalyzed reaction. ${ }^{[19]}$ However, this reaction is generally performed in toxic solvents such as dichloromethane and DMF. ${ }^{[20]}$ We found that, by using $1 \mathbf{c}$ as catalyst and butyl acetate as the solvent, the three-component reaction, although visibly under biphasic conditions, proceeded very well in these conditions, producing the benzofuran $\mathbf{7 a}$ in $97 \%$ yield (Table 1, entry 1). Under solvent-free conditions, likely due to the poor mass transfer efficiency resulting from the high viscosity of the ionic liquid, the yield of $\mathbf{7 a}$ reached only $31 \%$ (entry 2). Replacing $\mathbf{1} \mathbf{c}$ with triflic acid led to a homogeneous system, but the yield was significantly lower (22\%, entry 3$)$. This was expected, as the weakly polar butyl acetate solvent was reported to be less appropriate for the homogeneous acid-catalyzed reaction. ${ }^{[21]}$ Ionic liquids 1d and Forbes's ionic liquid 1e, although both also are strong acids and immiscible with butyl acetate, were found much less effective for the model reaction than 1c, leading to the expected product $7 \mathbf{a}$ in $69 \%$ and $48 \%$ yield respectively (entries 4 and 5). We also measured the acid strength of 1c and 1e by the Hammett method using 4-nitroaniline as an indicator. It was found that the acidities of them are quite similar (See ESI, Table S1). This implies that the acidity of the ionic liquid shouldn't be a reason to explain the good catalytic performance of 1c. A unique microenvironment created in the ionic liquid phase of $\mathbf{1 c}$ was thus expected to be responsible for such a significant improvement on the catalytic performance. Acid-stable solvents 1,2-dichloroethane (DCE), 1,4-dioxane, and acetonitrile are also unable to dissolve 1c, and thus form biphasic systems, however leading to slightly inferior yields (entries 6-8). A biphasic system composed of 1c and nitromethane gave 7a in $94 \%$ (entry 9), but nitromethane is not a relevant solvent in terms of greenness being toxic and explosive. Ethyl acetate was also examined and found to cooperate well with 1c, producing 7a in $84 \%$ yield, but was less appropriate due to its higher volatility compared to butyl acetate, only a part of solvent being liquid and playing the role of solvent (entry 10). Furthermore, the 1c/ethyl acetate system cannot be applied in the other reactions that would need high temperatures $\left(>80^{\circ} \mathrm{C}\right)$ due to lower volatility. The system 1c /butyl acetate was then selected for the next investigations in this study. When the catalyst 1c loading was decreased to 5 mol\%, the yield of $7 \mathbf{a}$ decreased to $75 \%$ (entry 11). Further investigations revealed that the reaction was also affected by temperature and reaction time, the optimal conditions being $80{ }^{\circ} \mathrm{C}$ and $2 \mathrm{~h}$ (entries 12 and 13).

The reaction using the $1 \mathbf{c} /$ butyl acetate system can be effectively scaled up with similar performance. For example, the reaction at $10.0 \mathrm{mmol}$ scale gave the corresponding product $7 \mathbf{a}$ in $96 \%$ yield ( $3.5 \mathrm{~g})$. In this case, the ionic liquid could be easily recovered and reused. Indeed, in the model reaction, 1c could be recycled at least five times without significant loss of activity (Figure 2).

It is worth noting also that, butyl acetate can be used as an extracting solvent to isolate the product from the ionic liquid. This allowed both the ionic liquid catalyst and butyl acetate to be recyclable. Although a very small part of butyl acetate (less than 5\%) was mechanically lost, the greenness of this reaction was 
thus further strengthened by the satisfactory recyclability level of both the ionic liquid and the solvent (Figure 3). Therefore, the ionic liquid 1c enabled us to establish an efficient acid catalytic system, fully recyclable, in combination with the use of a green organic solvent.

With the optimized conditions in hand, we investigated then the structural scope of the reaction with respect to all the three components, and the results are given in Scheme 2. Upon repeating the reaction with 5a and 6a, all indoles $4 \mathbf{a}$ exhibiting different functional groups on the arene ring worked well under the standard conditions, efficiently offering the corresponding functionalized C3-(indol-3-yl)-substituted benzofurans $7 \mathbf{b}-\mathbf{h}$ with yields ranging from $65 \%$ to $99 \%$. A variety of functional groups such as methyl (7d), ethyl (7b and 7e), phenyl (7c-e), bromo (7g), and methoxy (7h), can tolerate the acid-promoted conditions well. Resorcine $\mathbf{5 b}$ and phloroglucinol $\mathbf{5 c}$ participated readily in the reactions with $4 \mathbf{a}$ and $\mathbf{6 a}$, affording the desired products, $7 \mathbf{i}$ and $\mathbf{7 j}$, in $77 \%$ and $80 \%$ yields, respectively. Phenol was also tried but the reaction failed. This implies that an electron-donating activating group in the arene ring of the phenols is a requisite to facilitate the three-component assembly. Other alkylglyoxals were also used to react with 4a and 5a. In the biphasic system of 1c/butyl acetate, $7 \mathbf{k}$ can be formed in $77 \%$ yield from (4bromophenyl)glyoxal monohydrate. 2-Benzofuranylglyoxal hydrate was proven to be a viable substrate as well, the benzofuran fragment being delivered into the product without any structural damage (7l). Aliphatic alkylglyoxals are also amenable to 1c-catalyzed condensation with $\mathbf{4 a}$ and $\mathbf{5 a}$.

Methylglyoxal is commercially available as an aqueous solution (40 wt. \%). Despite the presence of water, it can be used uneventfully in our system. After $2 \mathrm{~h}$ of reaction at $80{ }^{\circ} \mathrm{C}$, the expected product $7 \mathbf{m}$ was isolated in $70 \%$ yield. Despite the cyclopropyl being an acid-labile group, the 1c/butyl acetate system allowed the reaction of cyclopropaneglyoxylaldehyde, $\mathbf{4 a}$, and $\mathbf{5 a}$ which proceeded smoothly, leading to the desired product $\mathbf{7 n}$ in $88 \%$ yield. Overall, the ionic liquid $\mathbf{1 c} /$ butyl acetate system is applicable in the reactions of structurally distinct indoles $\mathbf{4 a}-\mathbf{h}$, electron-rich phenols $\mathbf{5 a}-\mathbf{c}$, and alkylglyoxals $\mathbf{6 a}-\mathbf{e}$ with different electronic properties, thus providing an efficient and practical protocol for synthesizing richly decorated benzofurans such as $\mathbf{7 a - n}$. Compared with the previous catalytic system established in nitromethane, ${ }^{[21]}$ the use of butyl acetate as the solvent and 1c as the recyclable catalyst strengthens significantly the greenness of the methodology.

Inspired by these promising results, we investigated the applicability of the 1c/butyl acetate system in other organic reactions. The carbazole nucleus is the core unit of many therapeutic agents and organic photoelectronic materials and chromophores. ${ }^{[22]}$ Although a number of procedures have been developed and reported in literature, ${ }^{[23]}$ the indole-to-carbazole [4+2] annulation remains probably one of the most efficient way for synthesizing carbazoles. To meet the reactivity of 2,3-unsubstituted indoles, various 1,4biselectrophiles, such as 1,4-dicarbonyl compounds and their alkyne-, allene-, dihydrofuran-, and donorand-acceptor-cyclopropane-type variations, have been reported. ${ }^{[24]}$ However, most of these $1,4-$ biselectrophiles are not commercially available. As 2,5-dihydro-2,5-dimethoxyfuran contains two 
electrophilic centers, ${ }^{[25]}$ we conjectured that it might be a suitable 1,4-biselectrophic reagent to react with indole for synthesizing carbazole.

Preliminary experiments indicated that in the presence of a catalytic amount of triflic acid, 2,5-dihydro2,5-dimethoxyfuran could indeed react with two molecules of $N$-methylindole $4 \mathbf{i}$ to form carbazole derivative 8a (Scheme 3). However, the reaction had to be performed in nitromethane, giving 8a $61 \%$ yield after $2 \mathrm{~h}$ of reaction at $80{ }^{\circ} \mathrm{C}$. 1,4-Dioxane can also be a solvent for this reaction, but leading to a lower yield. To alleviate the detrimental effect of these toxic solvents, the reaction with triflic acid was performed in butyl acetate, but the yield reached only $50 \%$. However, when 1c was used as catalyst instead of triflic acid, the reaction in butyl acetate proceeded very efficiently with $\mathbf{8 a}$ being isolated in $91 \%$ yield. These results demonstrated that the biphasic system constructed by $\mathbf{1} \mathbf{c} /$ butyl acetate is the best one to ensure completion of the reaction.

For this reaction towards carbazole 8a, the ionic liquid 1d also effectively promoted the condensation reaction in butyl acetate, with a 70\% yield under identical conditions (Scheme 3). However, the real advantage of ionic liquid 1c is in catalyst recycling. While ionic liquid 1d gives only a moderate yield in the second run due to leaching of acid species, the efficiency of 1c was retained very well, with a $90 \%$ yield of 8a using the recovered 1c. The biphasic system composed of Forbes' ionic liquid 1e and butyl acetate was found inefficient for the synthesis of $\mathbf{8 a}$. After the three-component reaction of indoles shown previously, this reaction towards carbazole illustrates again that the use of 1c as a catalyst and butyl acetate as a solvent is able to promote the transformations of indoles while keeping out of the use of toxic dipolar aprotic solvents.

A scope of indoles was then subjected to the reaction with 2,5-dihydro-2,5-dimethoxyfuran (Scheme 3). Both electron-rich $(\mathbf{8 a}-\mathbf{c}, \mathbf{8 f}-\mathbf{h}$, and $\mathbf{8 k})$ and moderately electron-poor $(\mathbf{8 d}-\mathbf{e}$ and $\mathbf{8 i}-\mathbf{j})$ indoles readily reacted in this process. Somehow, $N$-benzylindole was not as reactive. Due to their poor nucleophilicity, indoles with a strong electron-withdrawing group such as 5-nitroindole and 5-cyanoindole, were unreactive in these conditions. Mechanistically, the synthesis of $\mathbf{8 a}$ is an acid-acid-catalyzed tandem reaction involving (i) the electrophilic ring-opening of 2,5-dihydro-2,5-dimethoxyfuran with two molecules of 4i, generating an intermediate I (Scheme 3); ${ }^{[26]}$ and (ii) the intra-molecular Diels Alder/methanol elimination of $\mathbf{I}$ to form $\mathbf{8 a} .{ }^{[27]}$ As indolyl-substituted carbazoles involve an expended $\pi$ conjugated system, these compounds are expected to be useful in strategies dedicated to the preparation of some photoelectronic materials. A method for synthesizing 1-(indol-3-yl)carbazoles was reported during the preparation of this manuscript by Nagarajan et al. ${ }^{[28]}$ The present protocol being able to produce 4-(indol-3-yl)carbazoles, offers thus a complementary route to access indolyl-substituted carbazoles.

Inspired by the above reaction, the protected thioacetal 9a was used as a 1,4-biselectrophile to construct a carbazole scaffold. ${ }^{[29]}$ As shown in Scheme 4, triflic acid was able to catalyze the [4+2] annulation of 9a and 4i. However, the reaction in nitromethane produced two regioisomers in nearly 1:1 ratio. After 2 
$\mathrm{h}$ of reaction at $80^{\circ} \mathrm{C}$, the total yield of $\mathbf{1 0 a}$ and $\mathbf{1 0 b}$ was $67 \%$. In acetonitrile, the yield of $\mathbf{1 0 a}$ slightly increased up to $40 \%$, while the yield of $\mathbf{1 0 b}$ remained nearly unchanged at $32 \%$.

When butyl acetate was used as the reaction solvent, the reaction proceeded sluggishly, with a total yield dropped to $20 \%$. Comparatively, when 1c was used as the catalyst and butyl acetate as the solvent, the $[4+2]$ annulation proceeded very well, with an $81 \%$ global yield. Remarkably, the regioselectivity was also significantly changed in favor of product 10a, with a 7/1 ratio for the carbazoles 10a/10b (Scheme 4). In this reaction, the ionic liquid $1 \mathrm{c}$ can also be recovered and reused with nearly the same performance.

The formation of the two products can be discussed in terms of the nucleophilicity of $\mathbf{4 i}$, as the $\mathrm{C} 2$ and $\mathrm{C} 3$ positions are both reactive nucleophilic sites, with the $\mathrm{C} 3$ one exhibiting generally higher reactivity than the $\mathrm{C} 2$ one. The electrophile, 9a, has also two different reactive sites, the ketone carbonyl group and, the acetal fragment. This latter undergoes deacetalization to form the aldehyde intermediate II. The carbazole products can be formed through two reaction pathways, which are: (i) the first-step push model, where the $\mathrm{C} 3$ position of $\mathbf{4 i}$ reacts first with the most reactive site of $\mathbf{I I}$, i.e. the aldehyde site, to form an intermediate III, after which the C2 position attacks the ketone carbonyl group, affording 10a (Scheme 5), and (ii) the second-step pull model, where the less reactive site of $\mathbf{4 i}$, the $\mathrm{C} 2$ position, reacts first with the aldehyde site of II, to form intermediate IV, after which the highly nucleophilic C3 position of the indole attacks the ketone carbonyl group, affording $\mathbf{1 0 b}$. In nitromethane, the two reaction models worked with the same kinetics, and therefore, nearly the same amounts of $10 \mathrm{a}$ and $\mathbf{1 0 b}$ were formed.

We conjectured that under biphasic conditions because most of the organic substances are contained in the butyl acetate organic phase, the reaction rate of deacetalization of $9 \mathbf{a}$ was decreased. Therefore, the concentration of the intermediate aldehyde II in the reaction mixture might be very low, giving the opportunity for the aldehyde to distinguish between the $\mathrm{C} 3$ position and $\mathrm{C} 2$ position of the indole ring based on their reactivity difference. Because the $\mathrm{C} 3$ position is the most favored to react with the aldehyde site, 10a was formed as the major product. This last example illustrates that besides the benefit in terms of yield and safety, the combined use of ionic liquid $\mathbf{1 c}$ as a catalyst and butyl acetate as a solvent is also able to influence the reaction selectivity.

It should be also noted that our reaction shown in Scheme 4 offers an alternative route to synthesize 1phenyl-9H-carbazoles under metal-free conditions, an alternative strategy compared to reported ones based on a Suzuki reaction which requires a $\mathrm{Cl}$ or $\mathrm{Br}$ substituent at the $\mathrm{C}-1$ position of carbazole and a noble-metal catalyst. ${ }^{[30]}$

\section{Conclusions}

With the aim of establishing novel catalyst and solvent conditions for some acid-catalyzed transformations of indoles avoiding the use of toxic and explosive dipolar aprotic solvents, a sulfonecontaining imidazolium-based Brønsted acid ionic liquid was designed and synthesized. The use of this 
tailor-made ionic liquid as an acid catalyst allows several selected transformation reactions of indoles to proceed very well in green and industrially acceptable solvent, butyl acetate. Because the ionic liquid is immiscible with butyl acetate, the reactions actually proceeded under biphasic conditions. This is beneficial to the recovery of the ionic liquid which can be recycled and reused with similar efficiency. The examples shown in this study illustrate that this catalytic system is not only able to increase the reaction yields, but also to alter the reaction selectivity. This work demonstrates that designing such innovative catalysts contribute to the replacement of less-green solvents by greener ones is a promising direction in catalysis research, and we are actively working in this direction.

\section{Experimental Section}

Melting points of the products were determined by microscopic melting point meter (Yu Hua Instrument, $\mathrm{X}-4) .{ }^{1} \mathrm{H},{ }^{13} \mathrm{C}$, and ${ }^{19} \mathrm{~F}$ NMR spectra were recorded on a Bruker AV-400 (400 MHz ${ }^{1} \mathrm{H}, 100 \mathrm{MHz}{ }^{13} \mathrm{C}, 375 \mathrm{MHz}{ }^{19} \mathrm{~F}$ ) at room temperature. Fourier transform infrared (FT-IR) spectra were recorded on a FT-IR Bruker (VERTEX 70) using liquid film technology. High-resolution mass spectra (HRMS) was recorded on a Bruker micrOTOF-Q II instrument. Ionic liquid 1d and 1e were prepared according to literature's methods with slight modification. ${ }^{[16,18]}$

\section{Synthesis of ionic liquid 1c}

Brønsted acid IL 1c was synthesized through the following three steps: (i) synthesis of 1a: in $100 \mathrm{~mL}$ round-bottomed flask equipped with mechanical stirring, an equal amount of divinyl sulfone $1 \mathbf{a}$ (5.0 g, $42.3 \mathrm{mmol}$ ) and 1-(3-aminopropanyl)imidazole (5.2 g, $42.3 \mathrm{mmol})$ were mixed in $75 \mathrm{~mL}$ of methanol; the mixture was stirred at $60{ }^{\circ} \mathrm{C}$ for $24 \mathrm{~h}$; then, volatile methanol was removed by a rotary evaporator; a yellow-pale oil was obtained, which is $\mathbf{1 a}$, in nearly quantitative yield. (ii) synthesis of $\mathbf{1 b}$ via quaternization: 1a (10.0 g, $41.1 \mathrm{mmol})$, 1,3-propanesulfonate (11.0 g, $90.4 \mathrm{mmol})$, and acetonitrile (75 $\mathrm{mL}$ ) were mixed in a $250 \mathrm{ml}$ round-bottomed flask equipped with mechanical stirring; the mixture was stirred at $80^{\circ} \mathrm{C}$ for $24 \mathrm{~h}$; a yellow solid was generated; then the solvent was decanted out; the yellow solid was filtrated, and washed with acetone $(5.0 \mathrm{~mL} \times 3) ; \mathbf{1 b}$ was obtained as a white solid which was then dried at $60^{\circ} \mathrm{C}$ under vacuum $(20 \mathrm{mmHg}$ ) for $4 \mathrm{~h}$; and (iii) acidification: $1 \mathbf{b}$ (10.0 g, $20.5 \mathrm{mmol})$ was mixed with triflic acid $(3.1 \mathrm{~g}, 20.5 \mathrm{mmol})$ in $25 \mathrm{~mL}$ of around bottomed flask; to facilitate the reaction, a small amount of water $(0.25 \mathrm{~mL})$ was also added in this step. Then, the mixture was stirred at $100{ }^{\circ} \mathrm{C}$ for $24 \mathrm{~h}$. The generated ionic liquid was washed with ethyl acetate $(5.0 \mathrm{~mL} \times 3)$ and diethyl ether $(5.0 \mathrm{~mL} \times 3)$; then, water and volatile solvents were removed under reduced pressure; finally, 1c was obtained as a yellow-pale viscous liquid. Over this three-step sequence, the ionic liquid 1c is obtained in $88 \%$ yield.

\section{Typical procedure for the reaction of phenylglyoxal monohydrate, sesamol and indoles}


All reactions were carried out in a $10 \mathrm{~mL} \mathrm{~V}$-type flask equipped with triangle magnetic stirring bar. In a typical reaction, 1c $(19.1 \mathrm{mg}, 0.03 \mathrm{mmol})$ was mixed with phenylglyoxal monohydrate (45.6 $\mathrm{mg}, 0.3$ mmol), sesamol (41.4 mg, $0.3 \mathrm{mmol})$ and 2-methylindole $(39.4 \mathrm{mg}, 0.3 \mathrm{mmol})$ in butyl acetate $(0.5 \mathrm{~mL})$. The mixture was stirred for $2 \mathrm{~h}$ at $80{ }^{\circ} \mathrm{C}$. After the completion of the reaction, the mixture was cooled to room temperature. Butyl acetate was decanted out, and the ionic liquid phase was extracted at $60{ }^{\circ} \mathrm{C}$ with butyl acetate $(0.5 \mathrm{~mL} \times 3)$. The product was obtained by isolation with preparative TLC (eluting solution: petroleum ether/ethyl acetate $=5 / 1_{\mathrm{v} / \mathrm{v}}$ ). The desired product $7 \mathbf{a}$ was obtained in $97 \%$ of yield. Tests for substrate scope were performed according to an analogous procedure.

Large scale synthesis of $\mathbf{7 a}$ was performed in a $25 \mathrm{~mL}$ single neck flask. Ionic liquid 1c $(0.64 \mathrm{~g}, 1.0$ mmol) was mixed with phenylglyoxal monohydrate $(1.52 \mathrm{~g}, 10.0 \mathrm{mmol})$, sesamol $(1.38 \mathrm{mg}, 10.0 \mathrm{mmol})$ and 2-methylindole $(1.31 \mathrm{~g}, 10.0)$ in butyl acetate $(15 \mathrm{~mL})$. The mixture was stirred for $2 \mathrm{~h}$ at $80{ }^{\circ} \mathrm{C}$. After the completion of the reaction, the mixture was cooled to room temperature. Butyl acetate was decanted out, and the ionic liquid phase was extracted at $60{ }^{\circ} \mathrm{C}$ with butyl acetate $(5 \mathrm{~mL} \times 3)$. The organic phase was dried over anhydrous $\mathrm{Na}_{2} \mathrm{SO}_{4}$. Then, the organic phase was subjected to distillation with a rotary evaporator to recover butyl acetate solvent. The residue was subjected to isolate with silica column chromatography (eluting solution: petroleum ether/ethyl acetate $=10 / 1_{\mathrm{v} / \mathrm{v}}$ ). The recovered ionic liquid was treated under reduced pressure for 30 minutes at $80^{\circ} \mathrm{C}$, and then used in the next run.

\section{A typical procedure for reaction of indoles and 2,5-dihydro-2,5-dimethoxyfuran}

In a typical reaction, 1c $(19.1 \mathrm{mg}, 0.03 \mathrm{mmol})$ was mixed with indole $(98.4 \mathrm{mg}, 0.75 \mathrm{mmol})$ and 2,5dihydro-2,5-dimethoxyfuran $(39.0 \mathrm{mg}, 0.3 \mathrm{mmol})$ in $1.0 \mathrm{ml}$ of butyl acetate. The mixture was stirred for $2 \mathrm{~h}$ at $80{ }^{\circ} \mathrm{C}$. After the completion of the reaction, the mixture was cooled to room temperature. The butyl acetate was decanted out, and the ionic liquid phase was extracted with butyl acetate $(0.5 \mathrm{~mL} \times 3)$. The organic phase was combined and then subjected to isolation with preparative TLC (eluting solution: petroleum ether/ethyl acetate $=20 / 1_{\mathrm{v} / \mathrm{v}}$ ). The desired product $8 \mathbf{a}$ was obtained in $91 \%$ of yield (calculated with respect to 2,5-dihydro-2,5-dimethoxyfuran). Tests for substrate scope were performed according to an analogous procedure.

\section{A typical procedure for reaction of indole and 1-((ethoxycarbonothioyl)thio)-4-oxo-4-phenylbutyl pivalate (9a):}

The reaction was carried out in a $10 \mathrm{~mL}$ of $\mathrm{V}$-type flask equipped with triangle magnetic stirring. Ionic liquid 1c (19.1 mg, $0.03 \mathrm{mmol})$ was mixed with indole $(39.4 \mathrm{mg}, 0.3 \mathrm{mmol})$ and 1((ethoxycarbonothioyl)thio)-4-oxo-4-phenylbutyl pivalate 9a (165.6 mg, $0.45 \mathrm{mmol})$ in $0.5 \mathrm{~mL}$ of butyl acetate. The mixture was stirred for $2 \mathrm{~h}$ at $90{ }^{\circ} \mathrm{C}$. After the completion of the reaction, the mixture was cooled to room temperature. The upper butyl acetate phase was decanted out, and the bottom ionic phase 
was extracted with butyl acetate $(0.5 \mathrm{~mL} \times 3)$. The organic phase was combined together and subjected to isolation with preparative TLC (eluting solution: petroleum ether/ethyl acetate $=50 / 1 \mathrm{v} / \mathrm{v}$ ). The desired product 10a and 10b were obtained in $71 \%$ and $10 \%$ yields, respectively. The recovered ionic liquid was treated at $100{ }^{\circ} \mathrm{C}$ under vacuum $(10 \mathrm{mmHg})$ for 30 minutes and then used in the next run.

\section{Acknowledgements}

The authors thank the National Natural Science Foundation of China (2171101076 and 21872060) and the Fundamental Research Funds for the Central Universities of China (2016YXZD033) for financial support. The Cooperative Innovation Center of Hubei Province is also acknowledged. Finally, support of HUST and the French ministry of Europe and Foreign Affairs to YQ visiting professorship is also gratefully acknowledged.

Keywords: ionic liquid $\bullet$ dipolar aprotic solvent $\bullet$ indole transformation $\bullet$ acid catalysis $\bullet$ green solvent

[1] a) T. P. Singh, O. M. Singh, Mini-Rev. Med. Chem. 2018, 18, 9-25; b) N. Chadha, O. Silakari, Eur. J. Med. Chem. 2017, 134, 159-184; c) D. Sunil, P. R. Kamath, Curr. Top. Med. Chem. 2017, 17, 959985; d) J. A. Homer, J. Sperry, J. Nat. Prod. 2017, 80, 2178-2187; e) T. V. Sravanthi, S. L. Manju, Eur. J. Pharm. Sci. 2016, 91, 1-10; f) M. -Z. Zhang, Q. Chen, G. -F. Yang, Eur. J. Med. Chem. 2015, 89, 421-441.

[2] a) S. W. Youn, T. Y. Ko, Asian J. Org. Chem. 2018, 7, 1467-1487; b) J. A. Leitch, Y. Bhonoah, C. G. Frost, ACS Catal. 2017, 7, 5618-5627; c) J. -B. Chen, Y. -X. Jia, Org. Biomol. Chem. 2017, 15, 3550-3567.

[3] a) Y. Chen, Z. Xie, Youji Huaxue 2012, 32, 462-471; b) M. Bandini, Org. Biomol. Chem. 2013, 11, 5206-5212; c) M. Platon, R. Amardeil, L. Djakovitch, J. -C. Hierso, Chem. Soc. Rev. 2012, 41, 39293968.

[4] a) M. Shiri, Chem. Rev. 2012, 112, 3508-3549; b) A. Palmieri, M. Petrini, R. R. Shaikh, Org. Biomol. Chem. 2010, 8, 1259-1270.

[5] a) Y. Gu, W. Huang, S. Chen, X. Wang, Org. Lett. 2018, 20, 4285-4289; b) F. Wu, W. Huang, Yiliqi; J. Yang, Y. Gu, Adv. Synth. Catal. 2018, 360, 3318-3330; c) C. Liu, W. Huang, M. Wang, B. Pan, Y. Gu, Adv. Synth. Catal. 2016, 358, 2260-2266; d) L. Min, B. Pan, Y. Gu, Org. Lett. 2016, 18, 364-367; e) C. Liu, L. Zhou, D. Jiang, Y. Gu, Asian J. Org. Chem. 2016, 5, 367-372; f) M. Li, Y. Gu, Adv. Synth. Catal. 2012, 354, 2484-2494.

[6] a) R. K. Henderson, C. Jiménez-González, D. J. C. Constable, S. R. Alston, G. G. A. Inglis, G. Fisher, J. Sherwood, S. P. Binks, A. D. Curzons, Green Chem. 2011, 13, 854-862; b) D. Prat, J. Hayler, A. Wells, Green Chem. 2014, 16, 4546-4551; c) S. Santoro, A. Marrocchi, D. Lanari, L. Ackermann, L. 
Vaccaro, Chem. Eur. J. 2018, 24, 13383-13390; d) S. Santoro, F. Ferlin, L. Luciani, L. Ackermann, L. Vaccaro, Green Chem. 2017, 19, 1601-1612; e) D. Prat, A. Wells, J. Hayler, H. Sneddon, C. R. McElroy, S. Abou-Shehada, P. J. Dunn, Green Chem. 2016, 18, 288-296; f) F. P. Byrne, S. Jin, G. Paggiola, T. H. M. Petchey, J. H. Clark, T. J. Farmer, A. J. Hunt, C. R. McElroy, J. Sherwood, Sustainable Chem. Proc. 2016, 4, 7/1-7/24; g) M. C. Bryan, P. J. Dunn, D. Entwistle, F. Gallou, S. G. Koenig, J. D. Hayler, M. R. Hickey, S. Hughes, M. E. Kopach, G. Moine, P. Richardson, F. Roschangar, A. Steven, F. J. Weiberth, Green Chem. 2018, 20, 5082-5103.

[7] a) R. A. Sheldon, Chem. Soc. Rev. 2012, 41, 1437-1451; b) J. Yang, F. Mei, S. Fu, Y. Gu, Green Chem. 2018, 20, 1367-1374; c) X. Yang, Y. Bao, Z. Dai, Q. Zhou, F. Yang, Green Chem. 2018, 20, 3727-3731; d) J. Xiao, H. Wen, L. Wang, L. Xu, Z. Hao, C. -L. Shao, C. -Y. Wang, Green Chem. 2016, 18, 1032-1037.

[8] Y. Ren, M. Li, J. Yang, J. Peng, Y. Gu, Adv. Synth. Catal. 2011, 353, 3473-3484.

[9] a) J. Sherwood, M. De Bruyn, A. Constantinou, L. Moity, C. R. McElroy, T. J. Farmer, T. Duncan, W. Raverty, A, J, Hunt, J. H. Clark, Chem. Commun. 2014, 50, 9650-9652; b) J. Zhang, G. B. White, M. D. Ryan, A. J. Hunt, M. J. Katz, ACS Sustainable Chem. Eng. 2016, 4, 7186-7192; c) L. Hughes, C. R. McElroy, A. C. Whitwood, A. J. Hunt, Green Chem. 2018, 20, 4423-4427; d) K. L. Wilson, J. Murray, C. Jamieson, A. J. B. Watson, Org. Biomol. Chem. 2018, 16, 2851-2854; e) A. Iemhoff, J. Sherwood, C. R. McElroy, A. J. Hunt, Green Chem. 2018, 20, 136-140; f) L. Mistry, K. Mapesa, T. W. Bousfield, J. E. Camp, Green Chem. 2017, 19, 2123-2128; g) J. E. Camp, ChemSusChem 2018, 11, 3048-3055.

[10] J. Sherwood, H. L. Parker, K. Moonen, T. J. Farmer, A. J. Hunt, Green Chem. 2016, 14, 3990-3996. [11] a) E. Petricci, C. Risi, F. Ferlin, D. Lanari, L. Vaccaro, Sci. Rep. 2018, 8, 10571. b) F. Ferlin, L. Luciani, S. Santoro, A. Marrocchi, D. Lanari, A. Bechtoldt, L. Ackermann, L. Vaccaro, Green Chem. 2018, 20, 2888-2893; c) F. Ferlin, S. Santoro, L. Ackermann, L. Vaccaro, Green Chem. 2017, 19, 2510-2514; d) S. Santoro, F. Ferlin, L. Luciani, L. Ackermann, L. Vaccaro, Green Chem. 2017, 19, 1601-1612; e) G. Strappaveccia, E. Ismalaj, C. Petrucci, D. Lanari, A. Marrocchi, M. Drees, A. Facchetti, L. Vaccaro, Green Chem. 2015, 17, 365-372; f) G. Strappaveccia, L. Luciani, E. Bartollini, A. Marrocchi, F. Pizzo, L. Vaccaro, Green Chem. 2015, 17, 1071-1076.

[12] S. G. Koenig, J. W. Dankwardt, Y. Liu, H. Zhao, S. P. Singh, ACS Sustainable Chem. Eng. 2014, 2 , 1359.

[13]A. Duereh, Y. Sato, R. L. Smith, H. Inomata, Org. Process Res. Dev. 2017, 21, 114-124.

[14] a) N. A. Isley, R. T. H. Linstadt, S. M. Kelly, F. Gallou, B. H. Lipshutz, Org. Lett. 2015, 17, 47344737; b) N. R. Lee, F. Gallou, B. H. Lipshutz, Org. Process Res. Dev. 2017, 21, 218-221.

[15]K. Zhang, X. -L. Li, S. -Y. Chen, H. -J. Xu, J. Deng, Y. Fu, ChemSusChem 2018, 11, 726-734. 
[16] a) A. Taheri, X. Pan, C. Liu, Y. Gu, ChemSusChem 2014, 7, 2094-2098; b) A. Taheri, C. Liu, B. Lai, C. Cheng, X. Pan, Y. Gu, Green Chem. 2014, 16, 3715-3719; c) A. Taheri, B. Lai, C. Cheng, Y. Gu, Green Chem. 2015, 17, 812-816; d) A. Taheri, B. Lai, J. Yang, J. Zhang, Y. Gu, Tetrahedron 2016, $72,479-488$.

[17]Q. Sun, S. Wang, B. Aguila, X. Meng, S. Ma, F. -S. Xiao, Nature Commun. 2018, 9, 3236.

[18] A. C. Cole, J. L. Jensen, I. Ntai, K. L. T. Tran, K. J. Weaver, D. C. Forbes, J. H. Davis, Jr. J. Am. Chem. Soc. 2002, 124, 5962-5963.

[19] a) G. -X. He, J. -M. Yuan, H. -M. Zhu, K. Wei, L. -Y. Wang, S. -L. Kong, D. -L.; Mo, X. -X. Pan, G. -F. Su, Bioorg. Med. Chem. Lett. 2017, 27, 1660-1664; b) H. R. Vahabinia, B. Karami, S. Khodabakhshi, J. Chin. Chem. Soc. 2013, 60, 1323-1327.

[20] a) C. -X. Chen, L. Liu, D. -P. Yang, D. Wang, Y. -J. Chen, Synlett 2005, 2047-2051; (b) A. Kundu,

A. Pramanik, Mol. Divers. 2016, 20, 619-626.

[21]C. Cheng, C. Liu, Y. Gu, Tetrahedron 2015, 71, 8009-8017.

[22] a) H. J. Knölker, K. R. Reddy, Chem. Rev. 2002, 102, 4303-4428; b) A. W. Schmidt, K. R. Reddy, H. J. Knölker, Chem. Rev. 2012, 112, 3193; c) J. Li, A. C. Grimsdale, Chem. Soc. Rev. 2010, 39, 2399-2410; d) F. Dumur, Org. Electron. 2015, 25, 345-361.

[23] a) B. Robinson, Chem. Rev. 1969, 69, 227-250; b) S. Muller, M. J. Webber, B. List, J. Am. Chem. Soc. 2011, 133, 18534-18537; c) V. P. Kumar, K. K. Gruner, O. Kataeva, H. J. Knölker, Angew. Chem., Int. Ed. 2013, 52, 11073-11077; d) H. Gao, Q. L. Xu, M. Yousufuddin, D. H. Ess, L. Kürti, Angew. Chem., Int. Ed. 2014, 53, 2701-2705.

[24] a) C. Kashima, S. Hibi, T. Maruyama, Y. Omote, Tetrahedron Lett. 1986, 27, 2131-2134; b) M. Kuroki, Y. Tsunashima, J. Heterocycl. Chem. 1981, 18, 709-714; c) Y. Matsuda, S. Naoe, S. Oishi, N. Fujii, H. Ohno, Chem. -Eur. J. 2015, 21, 1463-1467; d) X. Zheng, L. Lv, S. Lu, W. Wang, Z. Li, Org. Lett. 2014, 16, 5156-5159; e) J. Zhao, P. Li, C. Xia, F. Li, Chem. -Eur. J. 2015, 21, 6383-6457; f) Y. Matsuda, S. Naoe, S. Oishi, N. Fujii, H. Ohno, Chem. -Eur. J. 2015, 21, 1463-1467; g) B. Guo, X. Huang, C. Fu, S. Ma, Chem. -Eur. J. 2016, 22, 18343-18348; h) N. Thies, C. G. Hrib, E. Haak, Chem. -Eur. J. 2012, 18, 6302-6308; i) A. Kulkarni, P. Quang, B. Torok, Synthesis 2009, 23, 40104014; j) J. R. Stepherson, C. E. Ayala, T. H. Tugwell, J. L. Henry, F. R. Fronczek, R. Kartika, Org. Lett. 2016, 18, 3002-3005; k) J. Wu, Z. Yang, S. Zhang, C. Jiang, Q. Li, Z. Huang, H. Wang, ACS Catal. 2015, 5, 6453-6457; 1) A. Suárez, P. García-García, M. A. Fernández-Rodríguez, R. Sanz, Adv. Synth. Catal. 2014, 356, 374-382.

[25] a) R. Garzelli, S. Samaritani, C. Malanga, Tetrahedron 2008, 64, 4183-4186; b) H. Fontaine, I. Baussanne, J. Royer, Synth. Commun. 1997, 27, 2817-2824; c) C. Malanga, S. Mannucci, Tetrahedron Lett. 2001, 42, 2023-2025. 
[26] a) M. Li, J. Yang, Y. Gu, Adv. Synth. Catal. 2011, 353, 1551-1564; b) P. Ravichandiran, B. Lai, Y. Gu, Chem. Rec. 2017, 17, 142-183.

[27] a) C. Liu, Y. Gu, Adv. Synth. Catal. 2016, 358, 2260-2266; (b) C. Liu, B. Pan, Y. Gu, Chin. J. Catal. 2016, 37, 979-986.

[28]G. Ranjani, R. Nagarajan, Org. Lett. 2019, DOI: 10.1021/acs.orglett.8b03848.

[29] Compound 9a is not commercially available, and and can be synthesized via a two-step method. B. Quiclet-Sire, G. Sanchez-Jimenez, S. Z. Zard, Chem. Commun. 2003, 12, 1408-1409.

[30] a) C. Gao, Y. Sun, D. Cui, Y. Bi, W. Li, Faming Zhuanli Shenqing 2016, CN 105906549; b) H. S. Kim, D. -Y. Goo, S. K. Woo, Tetrahedron 2017, 73, 1413-1423.

${ }^{[31]}$ Table 1. Three-component reaction of $\mathbf{4 a}, \mathbf{5 a}$ and $\mathbf{6 a}$ under different conditions ${ }^{a}$

\begin{tabular}{|c|c|c|c|}
\hline [32] & 1d & 1c & le \\
\hline Entry & Solvent & Catalyst & $\begin{array}{l}\text { Yield } \\
(\%)\end{array}$ \\
\hline 1 & Butyl acetate & 1c & 97 \\
\hline 2 & - & 1c & 31 \\
\hline 3 & Butyl acetate & $\begin{array}{l}\text { Triflic } \\
\text { acid }\end{array}$ & 22 \\
\hline 4 & Butyl acetate & 1d & 69 \\
\hline 5 & Butyl acetate & 1e & 48 \\
\hline 6 & $\begin{array}{l}1,2- \\
\text { Dichloroetha } \\
\text { ne }\end{array}$ & 1c & 75 \\
\hline 7 & 1,4-Dioxane & 1c & 70 \\
\hline 8 & Acetonitrile & 1c & 80 \\
\hline 9 & Nitromethane & 1c & 94 \\
\hline 10 & Ethyl acetate & 1c & 84 \\
\hline
\end{tabular}




\begin{tabular}{|c|c|c|c|}
\hline 11 & Butyl acetate & $\begin{array}{l}\text { 1c } \\
\text { mol\%) }\end{array}$ & 75 \\
\hline 12 & Butyl acetate & 1c & $55^{b}$ \\
\hline 13 & Butyl acetate & 1c & $57^{c}$ \\
\hline
\end{tabular}

[33] ${ }^{a}$ reaction conditions: 4a, $0.3 \mathrm{mmol}$; 5a, $0.6 \mathrm{mmol}$, catalyst, $0.03 \mathrm{mmol}$; medium, $0.5 \mathrm{~mL}, 80{ }^{\circ} \mathrm{C}$, 2 h. ${ }^{b} 60{ }^{\circ} \mathrm{C} .{ }^{c} 1 \mathrm{~h}$.
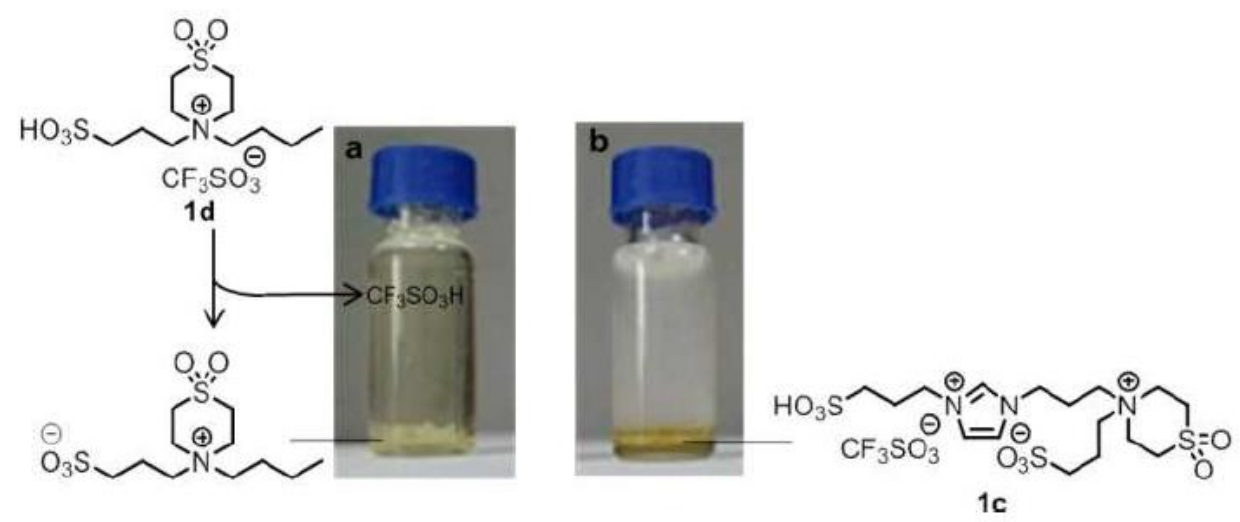

Figure 1. Mixing 1d or 1c with butyl acetate (picture a for 1d; picture b for 1c. Photos were taken after 5 minutes of shaking at room temperature).

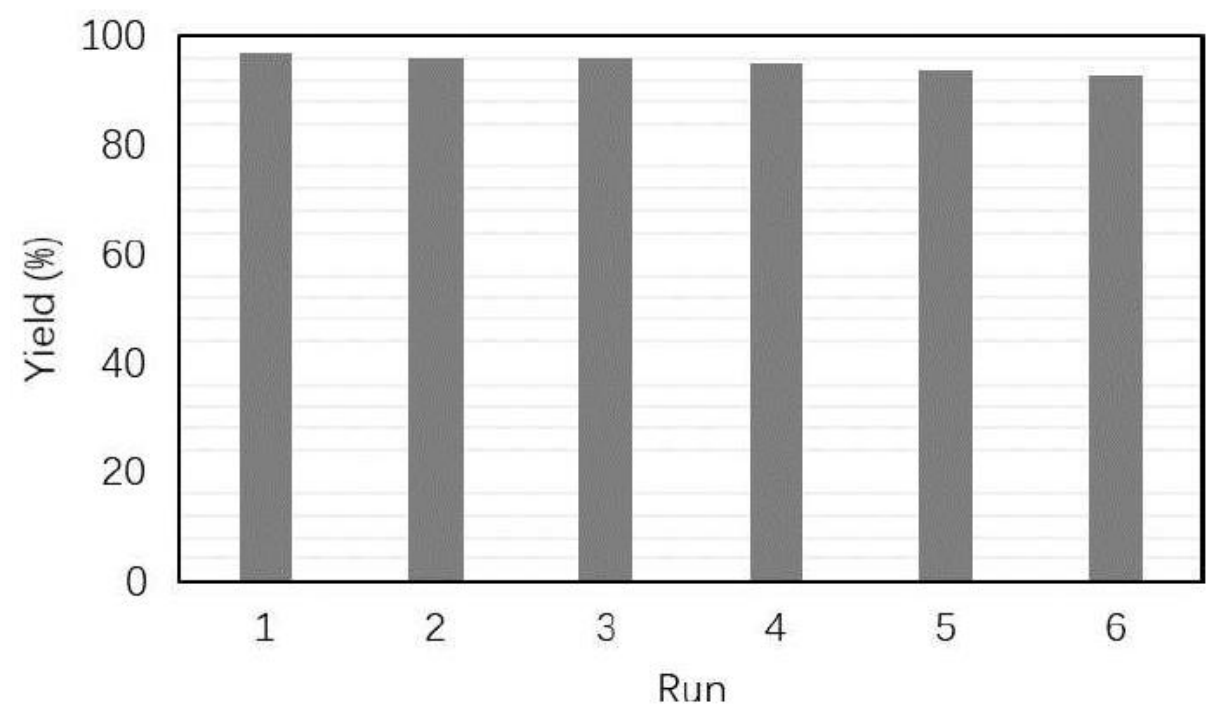

Figure 2. Recycling of $\mathbf{1 c}$ in the model reaction. 


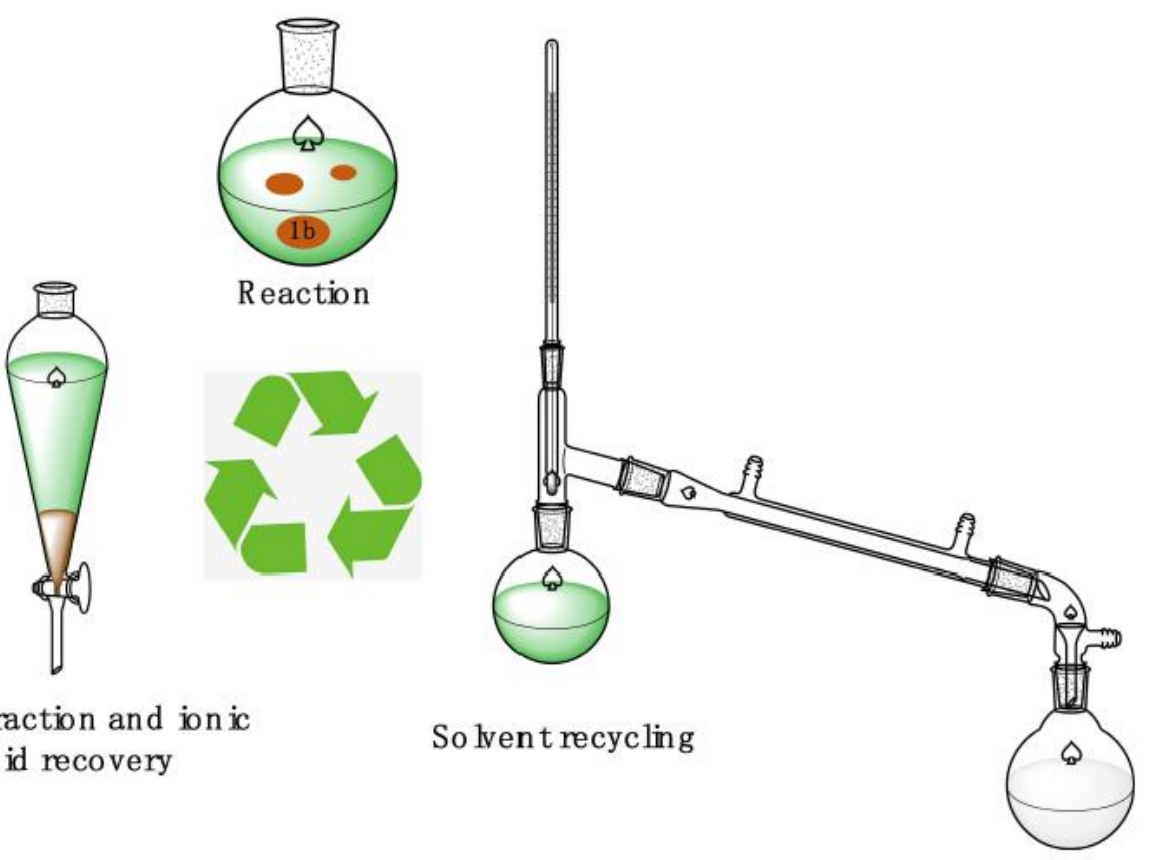

Figure 3. A schematic illustration of recycling butyl acetate solvent in the model reaction.

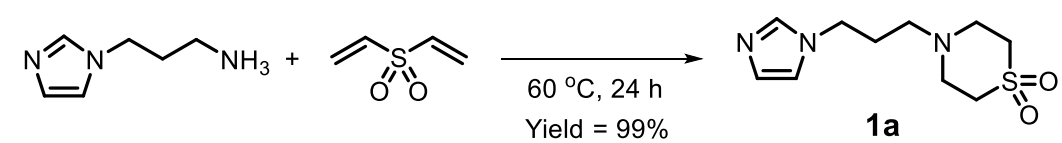<smiles></smiles><smiles></smiles>

Scheme 1. Preparation of ionic liquid 1c. 

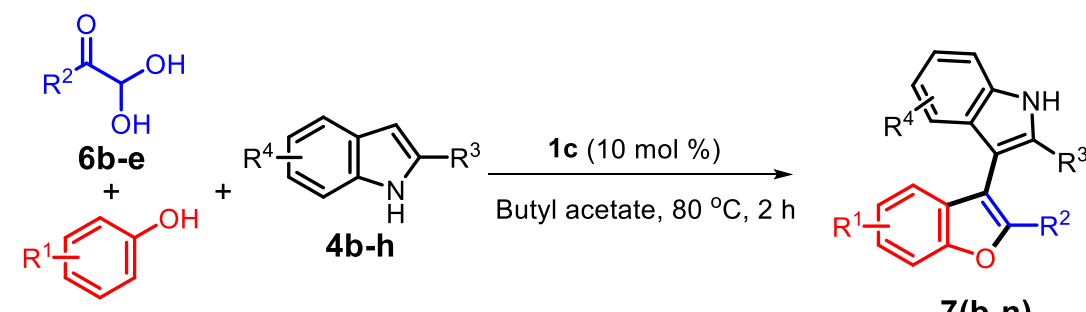

$5 b-c$

7(b-n)
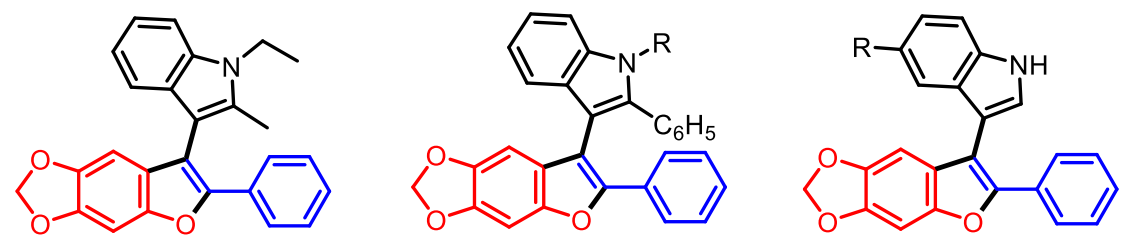

7b $95 \%$

7c $\mathrm{R}=\mathrm{H} \mathrm{99 \%}$

7d $\mathrm{R}=\mathrm{Me} 93 \%$

7f $\mathrm{R}=\mathrm{H} 75 \%$

7 e $\mathrm{R}=\mathrm{Et} 90 \%$

7g R $=\operatorname{Br} 65 \%$

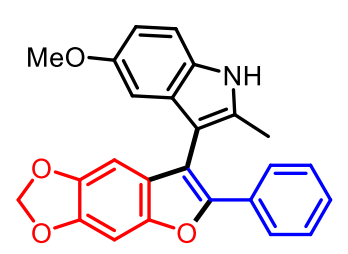

7h $80 \%$

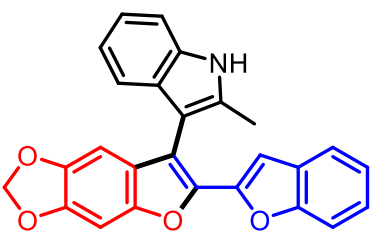

$7195 \%$

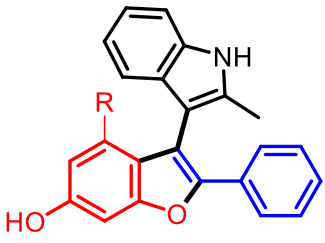

$7 \mathrm{i} \mathrm{R}=\mathrm{H} 77 \%$

7j $\mathrm{R}=\mathrm{OH} 80 \%$

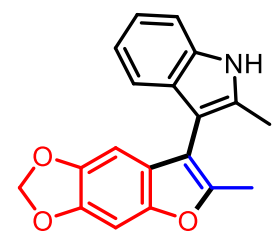

$7 \mathrm{~m} 70 \%$

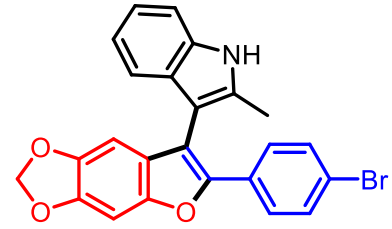

7k $77 \%$

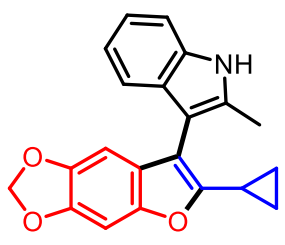

7n $88 \%$

Scheme 2. Scope of substrate of the model three-component reaction, 7(b-n). 


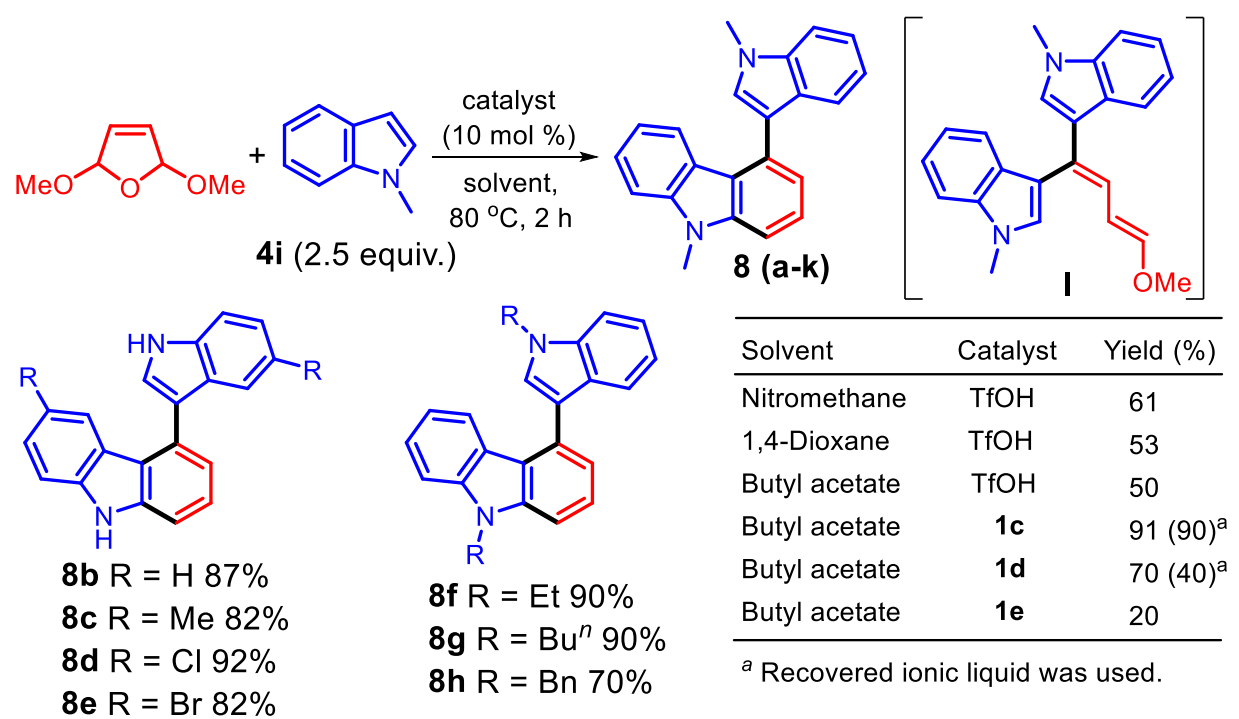

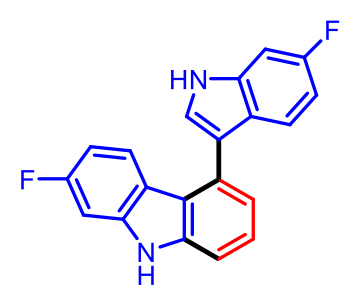

$8 \mathbf{i} 85 \%$

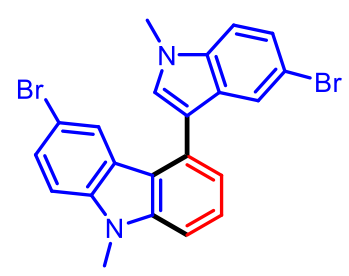

$8 \mathbf{j} 88 \%$

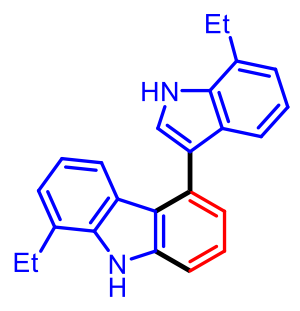

8 k $80 \%$

Scheme 3. Synthesis of carbazoles from indoles and 2,5-dihydro-2,5-dimethoxyfuran, 8 (a-k).<smiles>Cn1ccc2ccccc21</smiles>

$4 \mathbf{i}$<smiles>CCOC(=S)SC(CCC(=O)c1ccccc1)OC(=O)CC(C)C</smiles>

catalyst $(10 \mathrm{~mol} \%)$ tolvent, $90^{\circ} \mathrm{C}, 2 \mathrm{~h}$<smiles>Cn1c2ccccc2c2cccc(-c3ccccc3)c21</smiles>

$10 \mathrm{a}$<smiles>Cn1c2ccccc2c2c(-c3ccccc3)cccc21</smiles>

$10 \mathrm{~b}$

\begin{tabular}{llll}
\hline \multirow{2}{*}{ Solvent } & Catalyst & \multicolumn{2}{c}{ Yield (\%) } \\
\cline { 3 - 4 } & & 10a & 10b \\
\hline Nitromethane & TfOH & 34 & 33 \\
Acetonitrile & TfOH & 40 & 32 \\
Butyl acetate & TfOH & 11 & 9 \\
Butyl acetate & 1c & $71(70)^{\mathrm{a}}$ & $10(8)^{\mathrm{a}}$ \\
\hline
\end{tabular}

${ }^{a}$ Recovered ionic liquid was used.

Scheme 4. Synthesis of carbazoles via a [4+2] annulation of $4 \mathbf{i}$ and $9 \mathbf{a}$. 


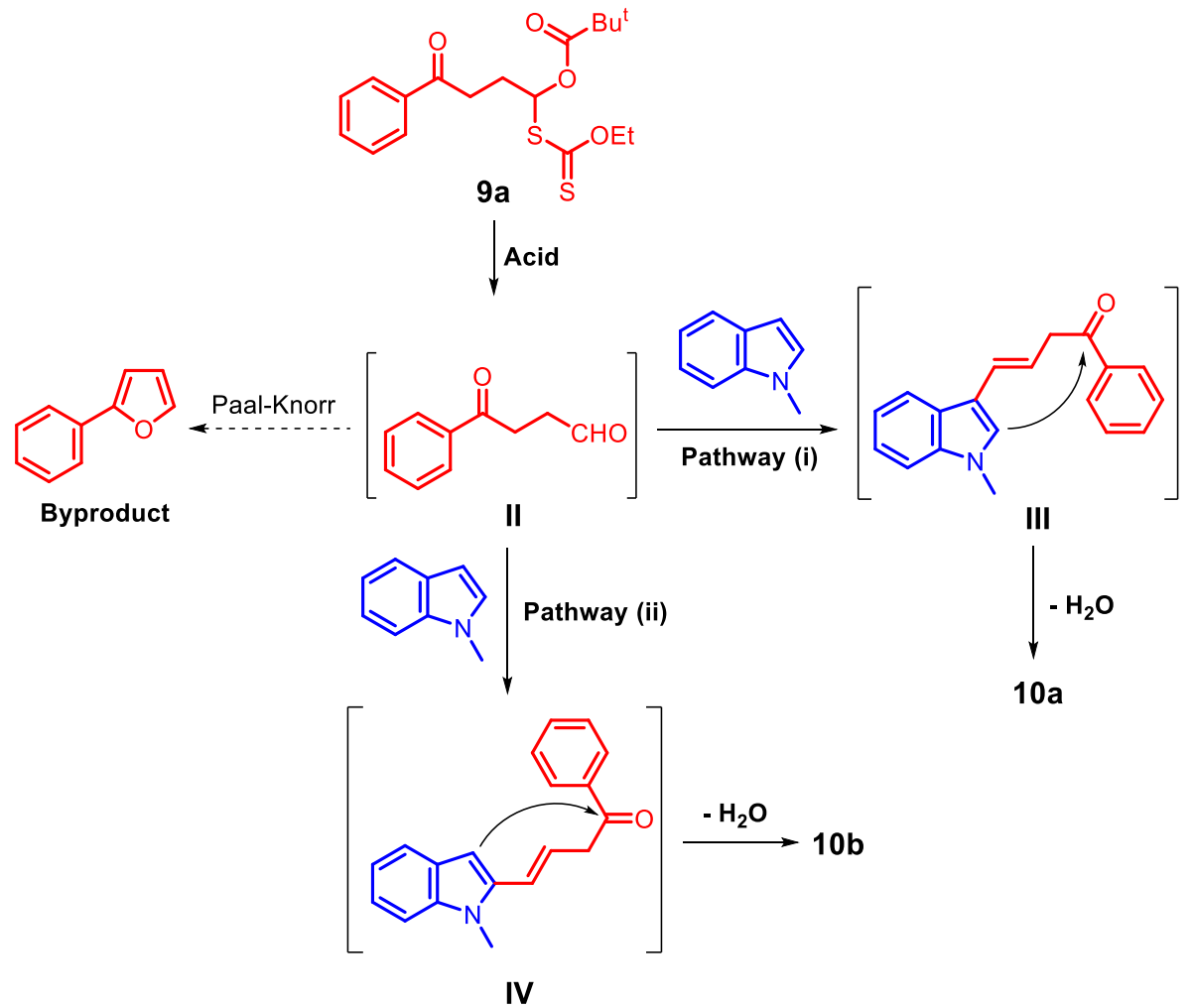

Scheme 5. Mechanism of the formation of $10 \mathrm{a}$ and $\mathbf{1 0 b}$. 